\title{
Mundo Rural e Historiografia Brasileira
}

Rural World and Brazilian Historiography

MOTTA, Márcia Maria Menendes. O Rural à la Gauche: campesinato e latifúndio nas interpretações de esquerda (1955-1996). Niterói: Editora da UFF, 2014. 278 p.

\section{Marcos Nestor Stein}

mancha36@hotmail.com

Professor do curso de graduação em História e do PPGH

Universidade Estadual do Oeste do Paraná

Rua Pernambuco, 1777

85960-000 - Marechal Cândido Rondon - Paraná

Brasil

Palavras-chave

Historiografia; Marxismo; História do Brasil.

Keywords

Historiography; Marxism; Brazilian History. 
A despeito da fala proferida pela senadora Kátia Abreu, em janeiro de 2015 - logo após assumir o cargo de ministra da Agricultura Pecuária e Abastecimento - na qual afirmava que o "latifúndio não existe mais" em nosso país, ${ }^{1}$ a história rural mantém-se firme na reflexão crítica em torno do mundo agrário e de suas relações atavicamente desiguais, tanto no Brasil quanto na América Latina. É nesse panorama que o livro "O Rural à La Gauche" da historiadora Márcia Maria Menendes Motta apresenta-se como uma leitura fundamental para a historiografia sobre o tema.

Redigido originalmente como tese para a ascensão de sua autora ao cargo de Professora Titular da Universidade Federal Fluminense, "O Rural à la Gauche" é um livro que apresenta uma pertinente análise de obras de cinco autores fundamentais - Nelson Werneck Sodré, Alberto Passos Guimarães, Caio Prado Junior, Maria Yedda Linhares e Ciro Flamarion Cardoso - para se compreender os debates e interpretações que envolvem a história do mundo rural brasileiro, bem como a constituição e consolidação da História Agrária como um importante campo científico.

A autora, Márcia Maria Menendes Motta, é atualmente uma das principais expoentes desse campo. Publicações de sua autoria como os livros "Nas Fronteiras do Poder" e "Dicionário da Terra", assim como o recém-lançado "O Rural à la Gauche", devem ser encaradas como leituras obrigatórias para todos aqueles que pretendem se embrenhar nos estudos sobre as dinâmicas presentes nas constituições dos espaços rurais brasileiros e as aventuras e desventuras de pessoas - camponeses, colonos, posseiros, agregados, meeiros, boias frias, etc.,- que buscaram e buscam viver de forma digna nestes espaços, marcados por constantes conflitos e onde ainda hoje o latifúndio é a regra.

A análise de interpretações sobre o mundo rural brasileiro e de propostas para a superação e/ou transformação de suas mazelas, produzidas entre 1955 e 1996 por intelectuais afinados e/ou inspirados em ideias comunistas, são o objetos centrais da narrativa de "O Rural à la Gauche". Em sua introdução são apresentados os autores com quem a autora dialoga e a seguinte linha de raciocínio que permeia as análises dos intelectuais acima citados:

[...] Quais eram as concepções que cada autor tinha acerca do universo rural brasileiro, em particular sobre campesinato e latifúndio. [...] Procuro também esquadrinhar como eles olharam o passado para conferir um sentido para os seus presentes. E mais: em que medida esses olhares eram possíveis no contexto da visão? (MOTTA 2014, p. 11)

Tais questões dão o tom da narrativa. Trata-se de uma linguagem clara e envolvente que, ao mesmo tempo, por meio do uso dessa chave de análise, permite ao leitor perceber o posicionamento teórico e político da autora, o rigor adotado no trato com os conceitos e o diálogo com a bibliografia - o que pode

\footnotetext{
${ }^{1}$ Kátia Abreu foi ministra da Agricultura, Pecuária e Abastecimento entre janeiro de 2015 e maio de 2016, durante o segundo governo de Dilma Rouseff. Atualmente é senadora pelo Tocantins, pecuarista e uma das maiores defensoras do agronegócio brasileiro. Para mais detalhes sobre a sua afirmação, ver: http:// www1.folha.uol.com.br/poder/2015/01/1570557-nao-existe-mais-latifundio-no-brasil-diz-nova-ministra-daagricultura.shtml.
} 
ser percebido, por exemplo, na introdução, quando chama a atenção para os "múltiplos marxismos" que constituem o pensamento comunista no Brasil e para a "[...] legitimidade do engajamento político como parte da formação do historiador" (MOTTA 2014, p. 22). ${ }^{2}$

A discussão que se segue está organizada em três partes. A primeira, intitulada "O Latifúndio na Perspectiva de um Brasil Feudal", está dividida em dois capítulos. No primeiro, a reflexão enfoca os escritos de Nelson Werneck Sodré (1911-1999), que advogava a tese de que o Brasil apresentava traços do sistema feudal que seriam originários de seu passado colonial. Os textos analisados são: "Oeste: Ensaio Sobre a Propriedade Pastoril", de 1941, "Formação Histórica do Brasil", cuja primeira versão é de 1944, "O que se deve ler para conhecer o Brasil", de 1943, e "As Razões da Independência", publicado em 1965.

Antes de iniciar a análise de seus escritos, Motta alerta para que não se encare a trajetória e o pensamento de Sodré de forma monolítica, ou somente como um autor "marxista", mas como um intelectual que produziu reflexões inspiradas em autores não marxistas e que são marcadas por descontinuidades e por rupturas. Tais considerações nos remetem às reflexões de Pierre Bourdieu (2002) acerca do caráter fragmentário das trajetórias de homens e mulheres, para as quais, muitas vezes por meio da narrativa biográfica, intenta-se constituir um sentido único, linear, totalmente coerente e ausente de hesitações, de dúvidas e de contradições.

Tomando esse cuidado, Motta sintetiza o pensamento de Sodré da seguinte forma:

Para Sodré, a formação do Brasil estaria assentada em duas contradições; internamente aquela que opunha senhores e escravos; externamente a que se expressava na relação entre metrópole e colônia. A articulação dialética entre ambas as contradições formaram o país e explicam a manutenção de relações atrasadas, de tipo feudal (MOTTA 2014, p. 36).

Trata-se, portanto, de um intelectual que encara o universo rural brasileiro como o lugar do atraso. De acordo com Motta, essa interpretação de Sodré perpassa inclusive os episódios de revolta dos pobres do campo, os quais são rotulados como fanatismos e/ou banditismo.

Ao final do capítulo, o leitor encontrará uma interessante análise acerca das leituras de Sodré que basearam seus textos mais importantes. Motta deixa claro que nem todos os autores, cujos escritos serviram de base para o autor construir sua tese, comungavam de sua visão. É o caso, por exemplo, de Roberto Simonsen e Caio Prado Junior, que rejeitavam a ideia da existência de um feudalismo no Brasil preconizada por Sodré, o que demonstra, portanto, o caráter plural de seu pensamento.

\footnotetext{
2 Esse posicionamento teórico e político - em grande parte inspirado no marxismo inglês, em especial nas reflexões de $\mathrm{E}$. P. Thompson - também está presente em sua produção bibliográfica, como no livro intitulado "Nas Fronteiras do Poder" (2008), na qual aborda os conflitos agrários no Brasil e as interpretações da legislação referente à posse e propriedade da terra, efetuadas por fazendeiros e trabalhadores rurais, e iniciativas em conjunto com outros pesquisadores brasileiros, como a criação da Rede Proprietas, um espaço dedicado ao debate acerca da noção de propriedade individual como algo natural e absoluta.
} 
O capítulo seguinte discute outro autor, Alberto Passos Guimarães (19081993), cuja interpretação, nas palavras de Motta, "[...] viria a dar uma visão mais acabada do feudalismo brasileiro [...]" (MOTTA 2014, p. 57). Ao analisar a obra de Passos Guimarães, a autora chama a atenção, inicialmente, para o pouco conhecimento acerca a importância de seus escritos, em especial o livro "Quatro Séculos de Latifúndio", publicado em 1963.

Na sequência, Motta realiza um minucioso exame do referido livro, analisando os argumentos e autores que Passos Guimarães utilizou para construir sua explicação de que o universo rural brasileiro, baseado na grande propriedade, constituiu-se a partir de um modelo transplantado de Portugal: o feudalismo. Para ele, essa estrutura manteve-se no Brasil com algumas modificações, em especial com a introdução do escravo em substituição ao servo.

Para Motta, essa intepretação, publicada um ano antes do golpe de 1964, deve ser vista também como um mecanismo de ação política, pois "[...] Guimarães acreditava que nominar de feudalismo a experiência colonial brasileira era a melhor forma de defender a reformulação da estrutura fundiária no país [...]" (MOTTA 2014, p. 63). Motta também incorpora em sua análise a edição de 1968 de "Quatro Séculos de Latifúndio", na qual Passos Guimarães anexou um capítulo sobre o Estatuto da Terra, e os estudos publicados no início da década de 1980, que abordam o desenvolvimento agrícola e a questão da violência no campo. Ao final, o leitor encontra um panorama detalhado dos autores citados por Passos Guimarães em cada capítulo de "Quatro Séculos de Latifúndio".

A segunda parte do livro, constituída por um capítulo, é dedicada ao pensamento de Caio Prado Junior (1907-1990), um grande crítico da tese do feudalismo brasileiro. Para investigar os argumentos de Caio Prado sobre o homem do campo e o latifúndio, Motta enfoca primeiramente a Revista Brasiliense, fundada em 1955, e que veio a se constituir em um espaço privilegiado da crítica à tese feudal preconizada pelo Partido Comunista Brasileiro. A partir dos artigos e da lista de colaboradores da revista, ela elenca e demonstra a importante dimensão que o tema relacionado à questão agrária teve na revista.

Na sequência, a análise se detém principalmente em três livros de Caio Prado Junior: "Formação do Brasil Contemporâneo", escrito em 1942, "História Econômica do Brasil", de 1945, e "A Revolução Brasileira", de 1966. Em sua investigação desse conjunto de textos, Motta revela os argumentos que o autor utilizou em seu embate com defensores da tese feudal acerca de temas envolvendo a colonização do Brasil, o latifúndio e os homens livres e pobres, estes caracterizados de forma depreciativa por Caio Prado Junior.

Ao final, na seção intitulada "Sodré, Passos Guimarães e Caio Prado: das recepções das obras", o leitor encontrará uma discussão que engloba tais autores, acompanhada por quatro quadros com informações sobre o número de edições, indicação do ano e das editoras. A apresentação das edições abre caminho para mais pesquisas sobre a recepção e as apropriações, os usos que cientistas sociais fizeram do pensamento desses intelectuais - tema que, sem dúvida, merece um livro a parte. 
A terceira parte do livro, dividida em quatro capítulos, enfoca de forma densa as trajetórias e obras de Maria Yedda Linhares (1921-2011) e Ciro Flamarion Cardoso (1942-2013), bem como a constituição e afirmação do campo científico da História Agrária. A análise inicia com informações sobre o trabalho de Linhares, em conjunto com outros intelectuais, durante período final da ditadura militar, quando da criação no Rio de Janeiro de um Centro de Pós-Graduação em Desenvolvimento Agrícola, de caráter interdisciplinar, cujo objetivo central era produzir conhecimentos sobre a agricultura brasileira e sua relação com o desenvolvimento do país. Em seguida, Motta faz um interessante mapeamento das publicações de Linhares que registram essa experiência, detendo-se no livro "História da Agricultura: combates e controvérsias", publicado em 1981, o qual também leva a assinatura de Francisco Carlos Teixeira.

O segundo capítulo dessa seção trata das reflexões de Jacob Gorender, seguida das de Ciro Flamarion Cardoso, ambos dedicados à construção de explicações acerca do sistema escravista no Brasil colonial. Em relação a Jacob Gorender, a análise de Motta enfoca as interpretações sobre os homens livres pobres, que na visão do autor ocupariam um lugar secundário na sociedade escravocrata. A discussão envolvendo as publicações de Ciro Flamarion Cardoso, em especial o livro "Agricultura, Escravidão e Capitalismo", de 1979, permite ao leitor compreender o processo de construção do conceito de modo de produção escravista-colonial e os debates envolvendo o conceito de modo de produção e a visão do autor acercado lugar dos camponeses - a "brecha camponesa" - nesse sistema/conceito.

Nos dois últimos capítulos, o leitor entrará em contato com uma análise acerca dos impactos dos livros de Linhares e Cardoso, a repercussão que o tema da questão agrária teve no Programa de Pós-graduação em História da UFF e o processo que viria a constituir o campo científico da história agrária. A narrativa é acompanhada por gráficos e de uma pertinente análise da conjuntura dessa produção: o processo de abertura política e os debates relacionados à reforma agrária travados por ocasião da elaboração da constituinte de 1988.

Trata-se, portanto, de um livro muito bem escrito, o qual, por um lado, não deixa de apontar as contradições e deficiências presentes nos textos dos autores analisados, e, por outro lado, também não deixa de reconhecer as suas contribuições para "[...] desnudar os caminhos e as mazelas da história rural do país" (MOTTA 2014, p. 250). Enfim, "O Rural à la Gauche" é um convite para a reflexão sobre esse seleto grupo de pesquisadores que, em diferentes momentos, interpretou a história do universo rural brasileiro e, sobretudo, merece ser lido em função do atual debate acerca da necessária transformação da estrutura fundiária do Brasil.

\section{Referências bibliográficas}

BOURDIEU, Pierre. A ilusão biográfica. In: AMADO, Janaína. FERREIRA, Marieta. (org.) Usos \& abusos da História Oral. Rio de Janeiro: Editora da FGV. 2002, p. 183-191. 
MOTTA, Márcia Maria Menendes. Nas fronteiras do poder. Conflito e direito à terra no Brasil do século XIX. Rio de Janeiro: Vício de Leitura; Arquivo Público do Estado do Rio de Janeiro, 1998.

. O Rural à la Gauche: campesinato e latifúndio nas interpretações de esquerda (1955-1996). Niterói: Editora da UFF, 2014. 